\title{
Sobre el donjuanismo de don Álvaro, del Duque de Rivas, en constante referencia a Félix de Montemar
}

\author{
José Luis Eugercios ARriero \\ Universidad Autónoma de Madrid - The George Washington University
}

Resumen: El don Álvaro de Rivas viene configurado como contrafacción del arquetipo donjuanesco que inaugura Tirso y lleva a plenitud Espronceda en El estudiante de Salamanca. El contraste entre las figuras de don Álvaro y don Félix ilumina al primero como burlador, cierto que a su pesar, y como elemento igualmente subversivo frente al orden sociomoral del antiguo régimen. En sus rígidos cánones hay que buscar las causas de la destrucción del indiano.

Palabras clave: Don Álvaro, Montemar, donjuanismo, honra, destino, Romanticismo

The womanizing in Duke of Rivas' Don Álvaro, in constant reference to Felix of Montemar

Abstract: Rivas has configured Don Álvaro as an investment in the literary type of Don Juan, inaugurated by Tirso and taken to its fullest expression by Espronceda in El estudiante de Salamanca. The contrast between Don Álvaro and Don Félix shows the former as an involuntary donjuán but, anyway, an element that is equally subversive against the social and moral order of the ancient regime. In its rigid canons the causes of the destruction of the indiano must be sought.

Keywords: Don Álvaro, Montemar, Don Juan, destination, honor, Romanticism. 


\section{UNAS NOTAS PREVIAS SOBRE EL DONJUANISMO Y SUS IMPLICACIONES IDEOLÓGICAS}

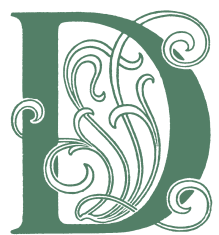

ifícilmente pasará de primeras el don Álvaro del Duque de Rivas por un don Juan ${ }^{1}$ avant la lettre puesto frente a los que conforman aquella estirpe que arranca del modelo tirsiano ${ }^{2}$ para alcanzar su plenitud con un satánico Félix de Montemar. Y desde ya avisamos, por cierto, que a nuestro juicio es este de Espronceda el que desarrolla el código donjuanesco hasta sus últimas consecuencias antes que aquel Tenorio al que Zorrilla condena a la redención por el amor, lo que no deja de ser una inversión del código fundante. Valga la comparación, de paso, para recordar que la recepción romántica del mito origina, sin salir de España ${ }^{3}$, piezas tan dispares como estas dos, amén de otros donjuanes menores y a menudo paródicos que se filtran todavía en alguna de las grandes novelas decimonónicas del paradigma realista-naturalista español ${ }^{4}$. Pues bien, aun aceptando que la de don Álvaro pueda antojarse aquí figura un tanto disonante, nos parece que Rivas ha configurado su personaje con un ojo puesto en este tipo literario al que tanta fortuna, esbozado queda, le cupo en el XIX.

A esta fortuna no le son ajenos los motivos ideológicos, puesto que el don Juan se alza como figura eminentemente subversiva y el Romanticismo es en gran medida reacción contra la pretendida armonía racional y moral propugnada por los ilustrados, según teorizó en su momento Romero Tobar (1994: 83). Así visto, la radical hipertrofia del yo creador, tan definitoria de

\footnotetext{
1 Así nos referiremos al tipo literario, prefiriendo esta grafía a la lexicalizada de donjuán, sin duda más contaminada por los usos cotidianos; aunque concederemos el plural donjuanes, así como los derivados donjuanismo y donjuanesco, a falta de mejores alternativas. En cuanto a que lo sea don Álvaro, algún trabajo se ha hecho en esta línea, como el de Navas Ruiz (1980), e incluso valdrá el de Hermosa Andújar (2001), con el Tenorio de Zorrilla siempre de fondo. Para la relación de Rivas con este último, ahora a propósito de El desengaño en un sueño (1842), véase Germán de Patricio (2009).

2 Damos el Burlador por obra de Tirso, sin aventurar conjeturas que escapan al objeto de este trabajo pero teniendo en cuenta las muchas y razonables sombras que arroja Rodríguez López-Vázquez (2018: 11-28) en su edición.

3 Fuera de nuestras fronteras piénsese en el Fausto (1808-1832) de Goethe, el Don Juan (1819) de Byron o ese caballero estético que describe Kierkegaard en sus Etapas en el camino de la vida (1845).

4 Nos referimos al Juanito Santa Cruz de Galdós y al Álvaro Mesía de Clarín, sobre quienes algo hemos escrito en esta dirección (Eugercios Arriero, 2018). En lo de considerar que, para el caso español, Realismo y Naturalismo se funden en un mismo paradigma somos deudores del magisterio del profesor Caudet Roca. A partir de aquí preferiremos, dado que la distinción y matices escapan a nuestro negociado, hablar de Realismo.
} 
este período, bien puede explicar y legitimar le recuperación de un mito que encarna como pocos la rebelión del individuo frente a lo general ${ }^{5}$. García Velasco refiere todo esto a «una atmósfera de hastío y repulsión» (2004: 269) y lo interpreta como «la explosión máxima de la ira contenida que estalla a causa de la impotencia que le provoca [al individuo romántico] la dolorosa realidad del mundo en el que vive» (2004: 270). Y nótese que el referente implícito es el individuo real porque, aun cuando nuestro objeto de estudio sean los personajes, tras ellos se ocultan unos autores ${ }^{6}$ de los que ya dijo Sebold (1983: 20) que se soñaban a sí mismos dioses: la propia García Velasco, poco antes de la cita recién traída, venía de decir cosa parecida al atribuirle a la sensibilidad del tiempo «el deseo incontenible de igualarse a Dios, de ser como Dios, para adquirir una fuerza titánica, imponente y demoledora» (2004: 269). Se trata, si bien se mira, de quella misma promesa bíblica que, puesta en boca de la serpiente, les había garantizado a los primeros padres de la humanidad la visión y el conocimiento divinos ${ }^{7}$; lo que pone de manifiesto el parentesco tan próximo de nuestro mito con otros de raíz más solemne, como puedan ser prometeísmo o satanismo, que aquí daremos por sinónimos ${ }^{8} \sin$ reparar en sus matices diferenciales por cuanto no son sino diversas maneras de manifestarse un mismo mitema, el de la rebelión y la caída, poco importa ahora si se trata de robar el fuego a los dioses clásicos o de rivalizar en belleza y sabiduría con el del Antiguo Testamento. Y no será precisa una lectura demasiado profunda para descubrir algo de ello en ese Montemar que era para Sebold «en lo moral hijo de Satanás y así encarnación del Anticristo» (1983: 206), y en el que Romero Tobar descubre una «sutil remodelación del anticristo en la inversión de los valores cristianos» (1994: 234). No agotaremos las citas en este sentido, sería tan sencillo como agotador, pero sí recordaremos que ya Rees (1979: 39) había subrayado cómo la interpretación romántica convierte a Lucifer en una figura «glamurosa». Le va bien el adjetivo, desde luego, a cuanto la crítica ha vertido sobre el es-

\footnotetext{
5 En el sentido kierkegaardiano (1998: 69), que identificaba lo general con la ética comunitaria.

6 Como especificaba Riley al teorizar sobre la novela cervantina: «A nadie se le ocurre pensar ni por un momento que la responsabilidad de la ficción no corresponda al autor, pero el lector es llevado fácilmente a aceptar esa simulación -y, por consiguiente, la ficción- como tal ficción» (1981: 317).

«Scit enim Deus quod in quocumque die comederitis ex eo, aperientur oculi vestri, et eritis sicut Deus scientes bonum et malum» $(G n 3,5)$.

8 Para Cortés Ahumada, el donjuanismo viene a contraponer razón y sentimiento hasta el extremo demoníaco, de modo que se convierte el individuo en «una especie de Prometeo cuyo conocimiento de lo inmediato lleva hasta el último latido» (1965: 1014).
} 
tudiante, consagrado como alter Deus español por antonomasia: el objeto último de su yo trascendentalizado sería, en palabras de Casalduero (1967: 172173), nada menos que el orden mismo del universo; idea que retoma García Velasco al adivinarle el própósito de «dominar [...] con su energía creadora el desorden del mundo» (2004: 274). Cómo quiera ordenarlo es razón que se nos escapa, ya decimos que la crítica se deja contagiar a menudo en su tono y conclusiones de la exaltación propia del período. Lo dicho, sin embargo, nos parece que se le puede aplicar, quizás con menos grandilocuencia pero no sin base textual, a don Álvaro, quien a su modo ha pretendido también asaltar el cielo 9 aspirando a un matrimonio que le estaba vedado, y suicida a fin de cuentas que muere encomendándose al mismo infierno (189). Y a los dos les valdrán, convengamos, las palabras de Rees sobre el primero: «a Promethean figure, representing human vitality and rebelion» (1979: 39). No extrañará que este espíritu de rebelión se le antoje tan especialmente propicio a su tiempo.

Diremos todavía una palabra algo más concreta sobre ello. Para la narrativa realista el don Juan, y aquí valdría ya donjuán, encarnará los vicios de la burguesía, piénsese en don Álvaro Mesía o Juanito Santa Cruz; pero los Clarín y Galdós escriben a la sombra del mito de la revolución traicionada, en este caso la Gloriosa de 1868, que, como es bien sabido, no trajo un nuevo orden sino la restauración borbónica ${ }^{10}$. Si nos hemos ido al último tercio del siglo, que es cuando los autores pueden constatar el fracaso de las revoluciones liberales, es porque el de Espronceda y Rivas es precisamente el tiempo de estas revoluciones, y las biografías del uno y el otro ${ }^{11}$ se entrelazan con la fortuna del liberalismo del XIX. En cierto modo, Romanticismo y Realismo son las dos caras de una misma moneda, la cara del antes y la del después ${ }^{12}$. La novela realista

\footnotetext{
9 Tienta la cita y, aunque descontexualizada, costaría imaginar otra que viniera mejor. Es la célebre de Marx en carta a Ludwig Kugelmann, con fecha 12 de abril de 1871, que leemos por Enríquez del Árbol (2007: 14).

10 Sobre la contextualización sociohistórica de la narrativa realista véase, para el caso de Galdós, el magnífico estudio de Caudet Roca (1992: 24-66) a propósito de Fortunata y Jacinta.

11 Puede repasarse la de Espronceda en el esbozo que ofrece Varela Jácome (1999: 11-16) antes de su edición. Para Rivas y su trayectoria véanse los trabajos de Martínez Torrón $(2010,2016)$ y el clásico de Boussagol, recientemente editado por Arroyo Almaraz (2019).

12 Conviene por ello matizar mucho aquella idea de que el primero surge sin más como reacción frente al Romanticismo, de la que ya sentenció Rodríguez Puértolas que «las cosas no son exactamente así» (2000: 319); y que también Joan Oleza ha refutado al argumentar cómo «buena parte de los elementos nucleares de una poética realista nacieron y se desarrollaron en el seno mismo del Romanticismo» (1998: 412).
} 
de tesis, concebida como instrumento crítico y corrector de la realidad social, coincidirá en el tiempo con la revolución industrial y la difusión de las ideas marxistas para hacerse ya eco de la dialéctica de clases. Llegados a este punto, el don Juan es un tipo literario un tanto trasnochado que, en parte por ello, les sirve a los novelistas para ilustrar cómo la burguesía ha traicionado, burlado si se quiere, al pueblo ${ }^{13}$; y si se le ajusta tan bien es por su voracidad y la inconsistencia de sus afectos. Pero en los años de Rivas y Espronceda esta misma voracidad y este mismo relativismo moral, la frivolidad que implican, pueden tener un sentido bien distinto. Venimos de apuntar que el XIX trae consigo la quiebra del optimismo racional ilustrado, hasta el punto de que parece que se anticipa ya en fecha tan temprana eso que la posmodernidad llamará caída de los metarrelatos, aquellos absolutos -la patria, la religión, las convencionesque se presentaban como garantía de sentido y verdad ${ }^{14}$. Con el medio siglo cundirá por la Europa post-hegeliana la crítica existencialista ${ }^{15}$ a los idealismos y Feuerbach va a sembar, en el seno del Romanticismo alemán, la semilla de la muerte de Dios. Aquel mismo Romanticismo, por cierto, que había inaugurado el Fausto de Goethe, de indudable raíz donjuanesca ${ }^{16}$. No se trata tampoco de forzar relaciones de necesaria causalidad, y menos de elevar de repente el mito a categoría filosófica, que sería tanto como incurrir en el exceso, siempre tentador, de hacerles decir a los textos cosas que quizás no dicen: la literatura es siempre, antes que otra cosa, literatura. Ahora bien, es además un producto histórico y, en cuanto tal, se deja contaminar por el momento en que surge, de manera que puede y debe leerse también desde la historia e, incluso, vale a veces como instrumento particularmente agudo para interpretarla. Y, para el caso que nos ocupa, lo cierto es que la hipertrofia del yo romántico, quintaesenciada en el don Juan, bien puede ser algo más que una evasión por la vía estética, puesto que presenta batalla abierta e irreverente a los esquemas sociomorales del antiguo régimen.

\footnotetext{
13 Por haber traído de la mano la restauración de la monarquía y del antiguo régimen cuando estaba llamada a abanderar el cambio social. Véanse las notas 4 y 10.

14 Venga al caso la cita ya clásica de Lyotard: «Dans la société et la culture contemporaine [...] le grand récit a perdu sa crédibilité, que soit le mode d'unification qui lui est assigné» (1979: 73).

15 Es verdad que justamente Sören Kierkegaard, inspirador de la reacción antihegeliana y precursor de todos los existencialismos, propone al don Juan como estadio llamado a la superación y no como modelo. No se puede olvidar, claro, que la filosofía kierkegaardiana es radicalmente cristiana, y que el individualismo que persigue es el de el hombre como único ante Dios.

16 Holthusen (1963) lo incluye entre los mitos o tipos literarios que en algún momento hayan podido se tomados como encarnación simbólica de la rebelión frente al destino o la colectividad, junto con Edipo, Hamlet o el mismo don Quijote.
} 
En este punto confluyen las figuras antagónicas pero paralelas de don Álvaro y don Félix de Montemar, quienes, cada cual a su modo, invierten el ideal del perfecto caballero español al profanar el más sagrado de sus valores, que es la honra con todo lo que implica ${ }^{17}$, y convertirse en elementos perturbadores de la armonía social. También, o sobre todo, y por encima de toda consideración de tipo moral a ojos del lector, don Álvaro, cuya historia debe contemplarse desde los de los Vargas si se quiere calibrar su verdadero alcance. Así las cosas, en uno y otro caso es válida la secuencia típica de seducción, burla y restauración; pero en uno y otro caso el pretexto de la trama se presta a lecturas más profundas ${ }^{18}$. En El estudiante, acaso la pieza más emblemática del Romanticismo español, seguramente la clave última sea la reivindicación de la libertad individual frente a toda opresión, que para Vasari (1980: 117) era el tema central de la obra. En lo que no acabamos de estar de acuerdo con este crítico o, por ajustar, lo que no vemos del todo claro en la obra, es que esta fuerza opresora sea la España concreta que identifica con «un cementerio, un castillo medieval, una iglesia arruinada, una ciudad llena de fantasmas y brujas» (1980: 98); como tampoco vemos, aunque la asociación resulte cuanto menos sugerente, que la frente descubierta de Montemar dispuesto al duelo frente a un embozado don Diego quiera ser símbolo del contraste «de las dos Españas, la retrógrada y la progresista» (1980: 110). No decimos que no fueran estas las ideas de Espronceda, quien seguramente las habría suscrito sin quitar un punto, sino que no las vemos en el texto con tanta claridad como Vasari. En cualquier caso, si traemos aquí al ilustre profesor es porque lo que lee en Espronceda nos parece que constituye la verdadera entraña de la obra de Rivas, donde un indiano sin linaje ni apellido desafía abiertamente al orden establecido, los sagrados cánones del honor y la casta, y muere por ello.

\section{DE ÁNGELES Y DEMONIOS}

Sin pretender componendas exegéticas que no vendrían del todo al caso, conviene recordar que para la tradición judeocristiana ángeles y demonios son

17 El teatro barroco nos enseña que la honra es ante todo un concepto sexual y social. En rigor la mujer no tiene honra, sino que es depositaria de la de su padre, esposo, prometido o hermano; y, pese a su crudeza, no les sobra una palabra a las bien conocidas de Quevedo en los Sueños: «La honra está junto al culo de las mujeres» (1984: 131). En cuanto a sus implicaciones sociales, valdrá como ejemplo cualquiera de los dramas de Lope o Calderón, pero nos permitimos destacar, del primero, El castigo sin venganza (1631), verdadera «figuración emblemática de la llamada ideología barroca» (Carreño, 2019: 49).

18 Que es justamente lo que sucede en la gran novela realista de folletín, desde Tolstoi a Galdós. 
una común sustancia, y que el Lucifer bíblico fue el más bello de los ángeles. De ahí el indudable potencial estético de su caída, que legitima la búsqueda de algún rastro formal de aquella belleza; $y$, al revés, justifica la sospecha de que cualquier ángel pueda pervertirse. Lo uno y lo otro se les puede aplicar, sin demasiado artificio, a Montemar y a don Álvaro. Del primero escribió Sebold que, «de haber usado sus enormes energías a otro efecto, [...] hubiera podido ser uno de aquellos capataces de la civilización en quienes la Ilustración veía los héroes que aseguraban a la humanidad un progreso infinito» (1978: 196). Desde luego que no tanto, es evidente el exceso que guía estas palabras, pero recuérdese que al estudiante «fuero le da su osadía, / le disculpa su riqueza, / su generosa nobleza, / su hermosura varonil» (vv. 128-131) ${ }^{19}$; más la célebre apostilla, quizás la que mejor lo define, de que «hasta en sus crímenes mismos, / en su impiedad y altiveza, / pone un sello de grandeza» (vv. 136-139). Por si esto fuera poco, échese un vistazo a los adjetivos positivos con que se le califica en la obra y que Varela Jácome, en el estudio preliminar a su edición, recoge ordenados algo parecido a un mapa conceptual ${ }^{20}$ : irónico, osado, noble, arrogante, rico, apuesto, valiente, valeroso. No encontramos en la tradición anterior caballero que aunase en su persona tantos y tan altos adornos.

Con semejante grado de estilización, necesariamente le irá a la zaga el indiano don Álvaro, pero no tanto dentro del universo particular en que se inserta, y su persona es descrita en términos menos deslumbrantes y más costumbristas que dan de resultas la figura de un perfecto caballero castellano: como «todo un hombre, muy duro con el ganado y muy echado adelante», lo presenta un majo; a lo que añade Preciosilla que es, además, «muy buen mozo» (47). Pero si en lo diabólico de Montemar cabría atisbar reminiscencia de un cierto brillo angélico, sobre don Álvaro se cierne desde el principio la sombra de la sospecha, por indiano, de origen incierto y sangre no limpia ${ }^{21}$,

\footnotetext{
19 Citamos El estudiante, como más adelante El burlador de Sevilla, dando los versos, según admite la hoja de estilo de esta revista y nos parece más ágil. No podemos hacer lo mismo con Don Álvaro, puesto que alterna verso y prosa. Para Rivas y Espronceda, a fin de ofrecer un texto más limpio, la referencia bibliográfica abreviada prescinde de autor y año de edición salvo que nos refiramos no a las obras sino a los estudios preliminares de, respectivamente, Benito Varela y Alberto Sánchez.

20 Al menos, esa forma les da: «su compleja etopeya forma una constelación, factible de representar con enlaces diagramáticos» (1999: 42); y ofrece a continuación (1999: 43) similar ordenación con los atributos de doña Elvira. En ambos casos nos parece aportación notable, o al menos práctica, la equematización, pero el editor no explica la lógica que guía esos «enlace diagramáticos».

21 Como nota curiosa, que no vinculante, Leon-Dufour (1967: 186) anota la asociación de los demonios veterotestamentarios con las divinidades paganas.
} 
según conoceremos más adelante. Son impedimentos mayores para quien aspire a ser tenido por caballero y, por de pronto, le alejan del canon donjuanesco convencional tal como lo sintetiza Rees: «noble blood, wealth, and good looks» (1979: 36); pero partimos del hecho que el personaje de Rivas no es un don Juan convencional, sino contrafacción del tipo literario. Además, este origen mestizo viene a sumarse al misterio que desde el comienzo lo envuelve. Recuérdese, a este respecto, su fantasmagórica aparición en esa acotación que por sí sola constituye toda la escena tercera de la tercera jornada:

Empieza a anochecer, y se va oscureciendo el teatro. Don Álvaro sale embozado en una capa de seda, con un gran sombrero blanco, botines y espuelas; cruza lentamente la escena, mirando con dignidad y melancolía a todos los lados, y se va por el puente. Todos lo observan en gran silencio (51).

Justo antes de la escena debatían unos cuantos secundarios acerca de tan misterioso personaje y precisamente un canónigo, no nos parece casual, se había preguntado: «pero, ¿quién es? » (49); a lo que respondería otro de los presentes que «un ente muy misterioso» (49). Nótese, por cierto, que el que hemos resaltado en cursiva es término procedente del ámbito de la metafísica, aun cuando puesto en boca de de un sencillo «habitante segundo» quizás no haya que sacarle más punta que a aquellas tiologías que no quería oír la Fortunata de Galdós. Volvamos, no obstante, a la silenciosa presentación del indiano, porque cada ademán y elemento escenográfico ${ }^{22}$ parecen destinados a ocultar la identidad del caballero y a marcar distancia con quienes lo observan. Rivas lo integra en la tradición folclórica española haciendo que se gane el aplauso del vulgo por su buena mano con el ganado o destacándose en los toros -costaría imaginar a Montemar en lides semejantes-, pero este mismo vulgo parece que intuye que el indiano no acaba de ser uno de los suyos.

Se trata, y es donde queremos llegar, de un personaje no menos misterioso que Montemar, a quien aventaja además en hondura psicológica: a trazo grueso podríamos decir que el indiano es un personaje redondo mientras que el estudiante es más bien plano, de «carácter rectilíneo» resume Varela

\footnotetext{
22 Aquí la acotación es contenido y viene a completar el retrato físico y moral del personaje. Recuerde el lector, al hilo de esto, las bien estudiadas de Valle-Inclán en cualquiera de sus esperpentos, su tan traído cinematografismo, y las palabras de Zamora Vicente a propósito de Luces de Bohemia: «[...] los contrastes de luz y de sombra [...], el ir y venir tembloroso de los personajes por las callejas madrileñas, bajo los fugaces resplandores de los faroles mortecinos, todo, todo es cine de la mejor ley» (2009: 28-29).
} 
Jácome (1999: 39), por cuanto no hay en él real evolución. Nos referimos, se entiende, a la hondura del personaje, no de la obra, y lo cierto es que se nos da como un ser apenas reflexivo, sin cosa parecida a la conciencia, a quien definen por encima de todo sus actos: «burlar, halagar, raptar, violentar y pasar corriendo». La cita es de Vossler (1995: 100) y, aunque referida al personaje de Tirso, entendemos que viene a cuento no ya solo por el carácter fundacional que ostenta este primer Tenorio sino, ante todo, por ese pasar corriendo que, siempre a nuestro juicio, constituye la principal nota definitoria del tipo donjuanesco: la huida constante no es evolución en el tiempo sino todo lo contrario, esto es salto hacia la repetición del mismo instante. En otra parte (2018: 101) hemos comentado cómo lo que define al tipo donjuanesco es el ser negación de la historia, y por esta vez creemos comprender a Casalduero cuando dice que el estudiante «sólo [sic] venciendo al tiempo con la velocidad se puede estacionar en el presente» (1967: 172); o a León Varela al afirmar que «Montemar sólo [sic] es en presente» (2003: 1025). Y todo esto, que bien pudiera parecer abstracción filosófica y algo de ello tiene, da razón cabal del personaje y de sus actitudes: no sufre, se hastía; no ama, burla; todo le aburre y siempre necesita volver a empezar en una suerte de eterno retorno a su condición primera y constante de seductor fugaz en quien solo la pulsión erótica ${ }^{23}$ y la codicia dicen de un ser de carne y hueso.

Especialmente llamativa resulta esta segunda, que nos parece aportación frente al modelo tirsiano ${ }^{24}$ y retrata a un don Juan cansado y casi en trámite de retiro ${ }^{25}$. Daremos algún botón de muestra: «necesito ahora dinero / y estoy hastiado de amores» (vv. 483-484); «mirad si me dais dinero» (vv. 541); y, sobre todo, en el diálogo previo al duelo con don Diego: «por vos / pierdo aquí una cantidad / considerable de oro / que iba a ganar... ¿y por qué? / [...] por no sé qué / cuento de amor» ${ }^{26}$ (vv. 655-660). La codicia enlaza directamente con la condición de jugador de Montemar, nueva aportación respecto

\footnotetext{
23 Véase al respecto el trabajo de Escobar (2006).

24 Podríamos aceptar, con Sáez, que al personaje de Tirso no le es ajeno este pecado, puesto que «roba el honor a hombres y mujeres y, materialmente, las monturas a la pescadora» (2010: 435); pero convéngase que tampoco lo define.

25 «Cuando don Félix actúa, ya no es por lo menos un don Juan joven, ilusionado, amante de las aventuras, sino un corazón gastado, un hombre maduro, frío en sus reacciones, y más interesado en el dinero que en otras cosas» (Navas Ruiz, 1990: 241).

26 Curiosamente, poco antes había mostrado cierto celo al reprochar a uno de sus rivales en el juego el hablar «con demasiada / altivez e irreverencia / de una mujer» (vv. 550-552): son palabras que damos por mera provocación.
} 
a los donjuanes precedentes sobre la que ya llamó la atención Marrast ${ }^{27}$ y le inspiró a Casalduero otro de esos juicios suyos tan poéticos que no nos atrevemos a desdecir ni alcanzamos a comprender: «en el tapete verde parece concentrarse el conflicto entre el hombre y su destino» (1967: 183). Sea más o menos profundo el simbolismo del tapete, repárese en el contrapunto con don Álvaro, que no juega pero debe irrumpir en una partida tramposa para salvar nada menos que a don Carlos, hermano de Leonor, que se ha dejado embaucar por un puñado de oficiales menores y no se basta por sí solo para salir airoso de «una cueva de ladrones» (111). No parece, tal como se nos pintan la escena y el personaje, un ambiente muy del gusto del indiano, que acude guiado ante todo por la amistad entrañable que le une al primogénito de los Vargas.

Pero también, interesa reparar en ello, el tenerse a sí mismo, frente a la soldadesca, «por caballero» (116), condición que se le ha reconocido mientras no se sabía su identidad: de sus modales había dicho un oficial, allá por la escena segunda de la obra, que «están pregonando que es un caballero», dando como prueba que «en el desafío que tuvo con el capitán de artillería se portó» como tal (48). Llegados los momentos de la verdad es dignidad que le será negada, como ya hizo el difunto primer marqués de Calatrava antes de su infortunado fin: «¿Tú morir a manos de un caballero? No; morirás a las del verdugo» (70). Poco le había importado que el indiano se arrojara a sus pies ofreciendo el pecho, actitud que en otro fuera noble pero para el viejo no indicaba sino «lo bajo de tu condición» (70). Es, pues, dignidad que se le niega a quien tanto ha querido merecerla ${ }^{28} \sin$ otra razón contraria que su condición de advenedizo ${ }^{29}$. Como al estudiante, se dirá, a quien don Diego tacha de mal caballero antes de batirse ambos (v. 673); pero no parece cosa

\footnotetext{
27 «Don Félix de Montemar n'est past seulement un calavera, bretteur en coureur de femmes comme le don Juan espagnol traditionnel; il est aussi joueur» (1974: 655). Por cierto que la escena de la partida le hace pensar a Varela Jácome «en el popularismo de los sainetes de Ramón de la Cruz, en el cuadro costumbrista inicial del Don Álvaro o la fuerza del sino» (1999: 37): no acabamos de ver clara la asociación.

28 Compárese con el don Juan de Tirso, que para sí la reclama ante las razonables dudas de don Gonzalo acerca de si cumplirá «una palabra / como caballero» (2007: vv. 2466-2467), se reivindica: «honor / tengo, y las palabras cumplo / porque caballero soy» (2007: vv. 2467-2469). Y es que al primer Tenorio sí le avala, pese a su corrupción moral y las reservas del padre infamado, el privilegio de un origen noble. Acerca de esto último, véase Sáez (2010: 433)

29 Quizás el adjetivo que mejor lo define, aunque Rivas tan solo lo emplea en dos ocasiones: en boca de ese «habitante segundo» que ya había avisado de que «el señor marqués de Calatrava tiene mucho copete y sobrada vanidad para permitir que un advenedizo sea su yerno» (48); y en la del propio marqués, quien lo tacha de «vil advenedizo» (70).
} 
que le importe al infamado. Nada que ver su despreocupación constante y su caracter burlesco, tomado el término ahora en su sentido más convencional, con ese don Álvaro capaz de sufrimiento y de conciencia ${ }^{30}$ a quien, paradójicamente, sus mejores intenciones van conduciendo al peor desenlace.

Y es un desenlace que al lector no deja de resultarle injusto contemplado desde una perspectiva moral. Si la perspectiva es de código la lógica se esclarece, porque el don Juan es inversión del perfecto caballero cristiano y, a tal efecto, ha de tener su persona la potencia de encarnarlo, recuérdese que hasta en sus actos más viles ponía Montemar aquel sello de grandeza. Los de don Álvaro puede que no hayan sido tan viles, pero ya avisamos más arriba que deben mirarse desde los ojos de esa biempensante sociedad sevillana en la que ha querido pasar por hombre de bien y, sobre todo, desde los de los Vargas. Y, así visto, de poco servirá que intente redimir sus culpas en la soledad de la celda monástica bajo la impostura del padre Rafael ${ }^{31}$ cuando, aunque no le habría cuadrado mal aquel célebre «clamé al cielo, y no me oyó» de Zorrilla, el cielo que le cierra las puertas no es el del Dios cristiano sino otro bien distinto, aquel en el que imperaba el difunto marqués de Calatrava y que, muerto este, acuden a sostener sus dos herederos. Es obvio que a sus ojos poco tendrá de ángel quien los ha ido matando.

\section{EL MUNDO Y LA SOCIEDAD: POÉTICA DE LA BURLA}

Si extraña este término, el de burla, aplicado al solemne personaje de Rivas, bien puede cambiarse por el de transgresión, más neutro. Ahora bien, que no le parezca un burlador al lector, e incluso que en puridad no lo sea, no quita para que por tal pase en el universo interno de la obra. El lector, claro, conoce que Leonor no ha sido deshonrada, que la muerte del marqués fue debida a un infortunio y que don Álvaro se vio empujado a sendos duelos con don Carlos y don Alfonso. Poco importa, porque por

\footnotetext{
30 Dos citas al respecto: cuando acude en socorro de don Carlos lo hace lamentando que «a los peligros voy / porque desgraciado soy» (116); y todavía al final de la obra, bien poco antes de su definitiva satanización, confiesa «la lucha / que conmigo estoy sufriendo» (175).

31 Marrast habla de un sentimiento íntimo de desazón, una «aspiration vers l'infini», que la literatura tradicional solo sabía resolver por el amor de Dios (1974: 663). Pudiera valer para el personaje de Zorrilla, ni modo para Montemar, y dado su desenlace suicida, entendemos que tampoco para la obra de Rivas. No se olvide, además, que la impostura del indiano al hacerse pasar por sacerdote es doble, porque ni lo es ni podría serlo, según propia confesión: «Estoy manchado de sangre, estoy irregular» (187).
} 
deshonrada pasa la dama ${ }^{32}$ que fue, además, sorprendida en trámites de fuga con quien acto seguido mataría a su padre y a sus hermanos: un historial digno del mismo Montemar, en quien venimos reconociendo la plenitud del mito.

Aun así, le seguirá pareciendo al lector que don Álvaro ha sucumbido frente a la fuerza de su oscuro sino, conforme anticipa el título de la obra. Por supuesto, pero un sino que poco tiene que ver con lo transcendente o sobrenatural y cuya razón se encuentra en ese entramado social en que irrumpe sin otra meta que los amores de una dama. Citaremos por enésima a García Velasco cuando define al estudiante como «un ser [...] enfrentado al mundo enemigo contra el que lucha» (2004: 269); y lo hacemos para nuevamente aplicar lo que de él se dice al personaje de Rivas, con más rigor, además, si cabe, puesto que no termina de estar claro qué cosa le haya hecho el mundo a don Félix mientras que para don Álvaro sí se presenta como una realidad hostil. Aunque, tal como acabamos de introducir, será más cabal hablar no tanto de mundo como de sociedad, porque el de mundo es concepto demasiado ancho y vago, y el muro contra el que topa una y otra vez el indiano, ya en España o en Italia, es el de la sociedad sevillana del «orgulloso clan de los Vargas», según anota Alberto Sánchez (2008: 26) en su prólogo. Véase el esquema de la burla en El estudiante según lo desbroza Varela Jácome (1999: 35; el sombreado es nuestro):

\begin{tabular}{|l|l|l|l|l|l|}
\hline Actante & éxito & $\begin{array}{l}\text { ruptura } \\
\text { contrato }\end{array}$ & $\begin{array}{l}\text { oponente } \\
\text { vengador }\end{array}$ & triunfo & castigo \\
\hline Don Félix & $\begin{array}{l}\text { amor } \\
\text { de Elvira }\end{array}$ & $\begin{array}{l}\text { abandono } \\
\text { de Elvira }\end{array}$ & Don Diego & le da muerte & $\begin{array}{l}\text { entra en el reino } \\
\text { de la muerte }\end{array}$ \\
\hline
\end{tabular}

E inténtese hacer algo parecido con el drama de Rivas. Reducirlo al mismo esquema sería tanto como castrar la trama, a no ser que añadamos un segundo nivel de perspectiva referido al asunto de clase:

32 Cosa que niega don Álvaro desde el primer instante, cuando le ofrece al marqués lavar con su sangre «la sospecha a que puede dar origen mi presencia aquí a tales horas» (71); y que volverá a negar ante Alfonso empeñando su palabra todavía como hombre de Dios: « ¡Mi Leonor! ¡Ah! No sin honra: / un religioso os lo jura» (176). Es curioso que aquí ponga por garantía de su palabra esa condición de religioso para la que, según apuntamos en la nota anterior, conoce que está inhabilitado. 


\begin{tabular}{|l|l|l|l|l|}
\hline Actante & éxito & $\begin{array}{l}\text { oponente } \\
\text { vengador }\end{array}$ & triunfo & $\begin{array}{l}\text { ruptura } \\
\text { contrato }\end{array}$ \\
\hline Don Álvaro & amor de Leonor & Marqués & le da muerte & $\begin{array}{l}\text { abandono } \\
\text { de Leonor }\end{array}$ \\
\hline Plano social & amenaza el orden social & $\begin{array}{l}\text { intento de } \\
\text { restauración }\end{array}$ & $\begin{array}{l}\text { rompe el orden } \\
\text { social }\end{array}$ & $\begin{array}{l}\text { verdadero } \\
\text { castigo }\end{array}$ \\
\hline
\end{tabular}

En ambos casos tenemos la forma externa de un asunto de honra, pero lo que en Montemar es su primera gran falta, el abandono de la dama, supone para don Álvaro el verdadero castigo, que viene acrecentado además por tener que cargar sobre su conciencia la muerte del padre vengador. Muerte no solo involuntaria, sino que se produce cuando el supuesto raptor está ofreciendo la propia vida en vano intento de restaurar ese orden social que un pistoletazo accidental termina de romper, de manera que ni es verdadero triunfo, difícilmente lo será dado el cómo se produce, ni la ruptura del contrato de amores es verdadera burla sino, en el fondo, cumplimiento póstumo de la voluntad del marqués. De hecho, y aun aceptando que a ojos de los Vargas pase por un burlador, su propósito era justamente todo lo contrario, puesto que aspiraba a casarse con Leonor y el matrimonio es la negación del donjuanismo ${ }^{33}$. Ahora bien, si ya su sola presencia resultaba inquietante en la alta sociedad sevillana, viene a colmar el vaso ese deseo suyo de contraer matrimonio con una dama honrada, cristiana y de noble cuna. Es entonces cuando el personaje pintoresco deviene en amenaza contra un sistema de valores, haciéndose precisa la receta que puntualmente ofrece, nuevamente no puede ser casual, el canónigo: «debe buscar otra novia» y desistir de «sus descabelladas pretensiones» (50). A Montemar lo habría redimido, de acuerdo con los cánones barrocos, restaurar la virtud de Elvira con un casamiento honroso, mientras que similar propósito es lo que termina de condenar a don Álvaro.

\section{CONDENA Y DESTINO}

Y lo condena sin que Dios ni el diablo tengan gran cosa que ver en el asunto. En el apartado anterior nos hemos quedado, cierto, a mitad de la trama. Lo que resta es la secuencia de dos nuevas muertes, las de esos dos nuevos

33 Recordaremos que para Kierkegaard el marido es figura simbólica del estadio ético 
oponentes vengadores que son los herederos del marqués de Calatrava, don Carlos y don Alfonso. Se trata de dos episodios casi calcados que dan lugar a una estructura recursiva y se ciñen al mismo patrón de huida, reencuentro, reconocimiento y duelo. Pasando por alto las diferencias entre uno y otro, que no son solo de matiz pero escapan ahora a nuestro negociado, lo cierto en que en los dos casos a don Álvaro termina por encontrarle ese destino funesto que, como dijimos más arriba, estamos leyendo desde una perspectiva de clase o casta y tiene que ver ante todo con su identidad, el misterio que siempre oculta ${ }^{34}$, lo que explica que «cada vez que se lo afean, monte en cólera, abandone sus pacíficas intenciones y dé muerte a quien ha osado recordarle su origen» (Cifo González, 2011: 27): por ello mata a Carlos, desmontada la máscara de Fadrique de Herreros; y a Alfonso, conocedor de que no existe el tal padre Rafael pero conocedor, sobre todo, de sus orígenes. No hay aquí un convidado de piedra ni una novia cadáver que lo lleve al infierno, sino que la satanización final del personaje, admítase que un tanto forzada, obedece a un desesperado movimiento de la propia voluntad; y así, por más que crea reconocer en el joven don Alfonso a un «hombre, fantasma o demonio / que ha tomado humana carne / para hundirme en los infiernos» (172-174), el indiano se precipita libre y consciente, terriblemente consciente: «yo soy un enviado del infierno, soy el demonio exterminador» (189). Si alguna vez se dijo que con el suicidio de Melibea en La Celestina había muerto la Edad Media, cosa similar ve Navas Ruiz en el del indiano, que «se alza en el momento mismo de arrojarse al abismo a la categoría de símbolo: símbolo de total rebeldía frente a una sociedad hostil e injusta» (1990: 184). Quizás habría salvado la vida si, como recomendaba el canónigo, hubiera buscado otra novia más acorde a su condición ${ }^{35}$.

¿Habría podido salvar Montemar la suya? A los infiernos baja, como don Álvaro, por su propio pie, aunque engañado porque «es bella la dama y aun fácil juzgó» (v. 912). Se trata de doña Elvira o, por mejor decirlo, del «esque-

\footnotetext{
34 Por traer una opinión contraria, a Rey Hazas (1986: 257, nota 15), en una de las aportaciones más agudas sobre la estructura de la obra, no terminase de parecerle que esto fuera tan determinante.

35 Del mal fin a que habrían de conducir estos amores ya avisó la criada Curra: «Mañana vería usted / revolcándose en su sangre, / con la tapa de los sesos / levantada, al arrogante, / al enamorado, al noble/ don Álvaro [...]» (58); y no le aguardaba a Leonor un destino menos oscuro, según había recordado poco antes Preciosilla: «iPobre niña! [...] Negra suerte le espera... Mi madre le dijo la buenaventura, recién nacida, y siempre que la nombra se le saltan las ságrimas» (51). Más allá del regusto costumbrista que le dan a la obra, se diría que estos personajes secundarios populares desempeñan también, a la manera de coro griego, una función expresiva y proléptica
} 
leto de la mujer que deshonró» (Silver, 1996: 46), y será quien, en curiosa reformulación del mito del convidado de piedra, les sirva de cebo a Dios o al diablo. Todavía concede Espronceda, sin embargo, que el ánima de la burlada trate de disuadir a su perseguidor, en un desesperado intento de salvarle que en cierto modo recuerda a la doña Inés de Zorrilla. Sea real este intento o, según preferimos, recurso del que se sirve el autor para dar nueva muestra de cómo la voracidad del estudiante no conoce límies, lo cierto es que no surte más efecto que el de avivar su ímpetu y, llegado el punto de no retorno, no le queda a Elvira, todavía la llamaremos así, exclamar aquello de «¡Cúmplase en fin tu voluntad, Dios mío» (v. 940), parafraseando las palabras de Jesús en el Huerto de los Olivos. De modo que, a lo que parece, sí habría podido salvar Montemar la vida. No la salva, como fuera, y cabe preguntarse a manos de quién la pierde. Se diría que, en efecto, se ha ha cumplido la voluntad de Dios, pero no parece tampoco que el estudiante lo tenga claro, aunque deja constancia de sus preferencias: «Mas antes decidme si Dios o el demonio / me trajo a este sitio, que quisiera ver / al uno o al otro, y en mi matrimonio / tener por padrino siquiera a Luzbel» (vv. 1542-1545). Tan solo por esta confesión, bien le vale a su descenso a los infiernos la denominación de nostos, por cuanto es retorno a la patria verdadera, y aceptamos la lectura de Romero Tobar, que descubre «resonancias del mito del paraíso perdido» que «conducen su significación a las connotaciones demoníacas» (1994: 234). No llegaremos al extremo de opinar que Montemar se redime en su condena: la angustiosa asfixia en que agoniza nos lo impide. Ahora bien, solo en el infierno real, demandando un cara a cara con el mismo Lucifer, despliega Espronceda el potencial de un personaje que hasta aquí, en la burla convencional, apenas había dado indicio de su verdadera esencia.

¿No sucede, podría pensarle, lo mismo con don Álvaro, quien no en vano termina reafirmándose como criatura diabólica? A similar fin llega, dijimos antes, pero por camino opuesto, porque antes de aquí todo en él fue reivindicar una condición distinta, la de caballero, que asociamos a lo angélico. Precisamente por ello nos parece que en su historia ha querido trazar Rivas, a modo de tragedia, el mito del ángel caído. Y, con todo, no es este, su principal hallazgo, sino el de haberse llevado el meollo del mito a la cuestión social. Sin entrometer ahora cuestiones extemporáneas relativas a la lucha de clases, concepto tan anacrónico como tentador, sí nos parece que la clave interpretativa más cabal para el drama de don Álvaro es su 
enfrentamiento donjuanesco con la casta de los Vargas y las convenciones sociomorales que encarna ${ }^{36}$. De poco le habrían de servir la honradez de sus propósitos, el llanto contrito por los muertos que mató, su apelación a lo sagrado, cuando ni el juez que lo juzgaba era el Dios cristiano ni había tampoco manera de lavar esa mancha de una genealogía vil que lo inhabilitaba genéticamente para emparentar con una Vargas. Quizás fue este primer deseo no solo la causa del resto de sus culpas, sino la más grave de todas ellas; y quizás Rivas, al quererlo así, estaba introduciendo en el drama romántico el concepto de determinismo social.

\section{REFERENCIAS BIBLIOGRÁFICAS}

CARreño, Antonio (2019), «Introducción» a Lope de Veda, El castigo sin venganza, Madrid, Cátedra, págs. 15-100.

CAsalduero, Joaquín (1967), Espronceda, Madrid, Editorial Gredos.

CAudet Roca, Francisco (1992), «El referente socio-histórico», en Benito Pérez Galdós, Fortunata y Jacinta, edición de Francisco Caudet, vol. I, Madrid, Cátedra, págs. 24-44.

Cifo González, Manuel (2011), «El poder del hado en La vida es sueño, de Calderón de la Barca y en Don Álvaro o la fuerza del sino, del Duque de Rivas Autores», en Estudios humanísticos. Filología, 33, págs. 91-110.

Cortés Ahumada, Ernesto (1965), «El donjuanismo como conocimiento», en Boletín Cultural y Bibliográfico, vol. 8, 7, págs. 1008-1014.

Boussagol, Gabriel (2019), Ángel de Saavedra, duque de Rivas. Su vida, su obra literaria, edición de A. Arroyo Almaraz, Sevilla, Alfar.

36 Citamos por extenso las conclusiones de Rey Hazas: «Don Álvaro o la fuerza del sino es una tragedia total [...] que inserta un problema social dentro de un ámbito filosófico que lo trasciende [...]. El protagonista es, en principio, un ser nada rebelde, marcado por un estigma familiar de mestizaje y traición a la corona que le obliga a saltarse el código social imperante para conseguir su amor. Pero nunca pone en duda la validez de las normas sociales, pues su orgullo de caballero implica que las acepta» (1986: 259). Sobre esto último, que acepte las normas sociales, habría todavía mucho que matizar. Concedemos que las acepta cuando empeña palabra y vida por salvar el buen nombre de Leonor o la honra familiar de los Vargas; pero previamente las ha desafiado y, recuérdese, el pretenderse caballero no le basta para serlo. 
De Patricio, Germán (2009), «Soñando juntos. Contexto y siglos de oro en El desengaño en un sueño" del Duque de Rivas, y sus contactos con Don Juan Tenorio de Zorrilla», en Boletín de la Biblioteca de Menéndez Pelayo, 85, págs. 247-264.

DuQue de Rivas [Ángel de Saavedra] (2008), Don Álvaro o la fuerza del sino, edición de Alberto Sánchez, Madrid, Cátedra.

ENRíQuez del Árbol, Carlos (2007), «La comuna, Rimbaud y Lenin», en Filosofía, política y economía en el Laberinto, 24, págs. 6-15.

Escobar, José (2006), «Don Juan, vendaval erótico romántico, en Espronceda y Zorrilla», en Actas del IX Congreso del Centro Internacional de Estudios sobre Romanticismo Hispanico [Saluzzo, 17-19 de febrero de 2005], págs. 65-79.

Espronceda, José de (1999), El estudiante de Salamanca, edición de Benito Varela Jácome, Madrid, Cátedra.

García Velasco, Juncal (2004), «El satanismo en Espronceda», en Revista de Estudios Extremeños, 69, págs. 269-288.

Hermosa Andújar, Antonio (2001), «Las tragedias del amor (amor, honor y sociedad en Don Alvaro o la fuerza del sino), en Araucaria: Revista Iberoamericana de filosofía, política y humanidades, 5, págs. 19-56.

Holthusen, Hans Egon (1963), «¿Qué es lo occidental? Cinco figuras directrices de la literatura europea», en Eco, 7, págs. 427-455.

KierKegaARD, Sören (1998), Temor y temblor, traducción de Vicente Simón Merchán, Madrid, Tecnos.

LeÓN VARela, Victoria (2003), «El estudiante de Salamanca y el Canto a Teresa: la Sehnsucht titánica de Espronceda», en Revista de Estudios Extremeños, 59, págs. 1017-1036.

LÉOn-Dufour, Xavier (1967), Vocabulario de teología bíblica, Barcelona, Herder.

LYOTARD, Jean-François (1979), La condition postmoderne. Rapport sur le savoir, París, Les Editions de Minuit. 
MARRAST, Robert (1974), José de Espronceda et son temps. Littérature, société, politique au temps du Romantisme, París, Editions Klincksieck.

MARTínez Torrón, Diego (2010), El universo literario del Duque de Rivas, Sevilla, Alfar.

- (2016), «Volver al Duque de Rivas», en Diego Martínez Torrón (coord.), Recuperar al Duque de Rivas, Sevilla, Alfar, págs. 49-60.

Navas Ruiz, Ricardo (1980), «Don Álvaro y Don Juan. Contribución a una mitología romántica española», en Cuadernos para la investigación de la literatura hispánica, 2-3, págs. 161-170

- (1990), El Romanticismo español, Madrid, Cátedra.

OlezA, Joan (1998), «La génesis del Realismo y la novela de tesis», en L.Romero Tobar (ed.), El siglo XIX, II (= Historia de la literatura española), Madrid, Espasa Calpe, págs. 410-435.

Quevedo, Francisco de (1984), Los sueños, edición de M. Etreros, Barcelona, Planeta.

ReEs, Margaret A. (1979), Espronceda. El estudiante de Salamanca, Londres, Grant \& Cutler.

Rey HazAs, Antonio (1986) «La insólita estructura de "Don Álvaro o la fuerza del sino», en Anuario de estudios filológicos, 9, págs. 249-261.

RILEy, Edward C. (1981), Teoría de la novela en Cervantes, Madrid, Taurus.

RodríGuez PuÉrtolas, Julio (2000), «Realismo, Realismos, realidad: entre espejos anda el juego», en Príncipe de Viana. Anejo, 18, págs. 319-329.

Romero Tobar, Leonardo (1994), Panorama crítico del Romanticismo español, Madrid, Castalia.

SÁeZ, Adrián J. (2010), « El burlador Don Juan: las burlas por la honra y el amparo de la sociedad», en Álvaro Baraibar Echeverria, Tapsir Ba, Ruth Fine y Carlos Mata Induráin (eds.), Textos sin fronteras: literatura y sociedad, Navarra, EUNSA, págs. 427-440. 
SEbold, Russell P. (1978), «El infernal arcano de Félix de Montemar», en Hispanic Review, 46.4, págs. 447-464.

- (1983), Trayectoria del Romanticismo español. Desde la Ilustración hasta Bécquer, Barcelona, Editorial Crítica.

SILVER, Philip W. (1996), Ruina y restitución: reinterpretación del Romanticismo en España, traducción de José Luis Gil, Madrid, Cátedra.

Tirso De Molina (2007), El burlador de Sevilla, edición de I. Arellano, Madrid, Austral.

- (2018), El burlador de Sevilla o El convidado de piedra, edición de A. Rodríguez López-Vázquez, Madrid, Cátedra.

VASARI, Stephen, «Aspectos religioso-políticos de la ideología de Espronceda: El estudiante de Salamanca», en Bulletin Hispanique, 82.1-2, págs. 94-149.

VossLer, Karl (1965), Lecciones sobre Tirso de Molina, Madrid, Taurus.

Zabala, Iris M. (1982), «Románticos y liberales», en Iris M. Zabala (Coord.), Románticos y liberales [= Historia y crítica de la literatura española, dir. F. Rico, vol. V), págs. 7-19.

ZAmora Vicente, Alonso (2009), «Introducción» a Ramón del Valle-Inclán, Luces de Bohemia, Madrid, Austral. 


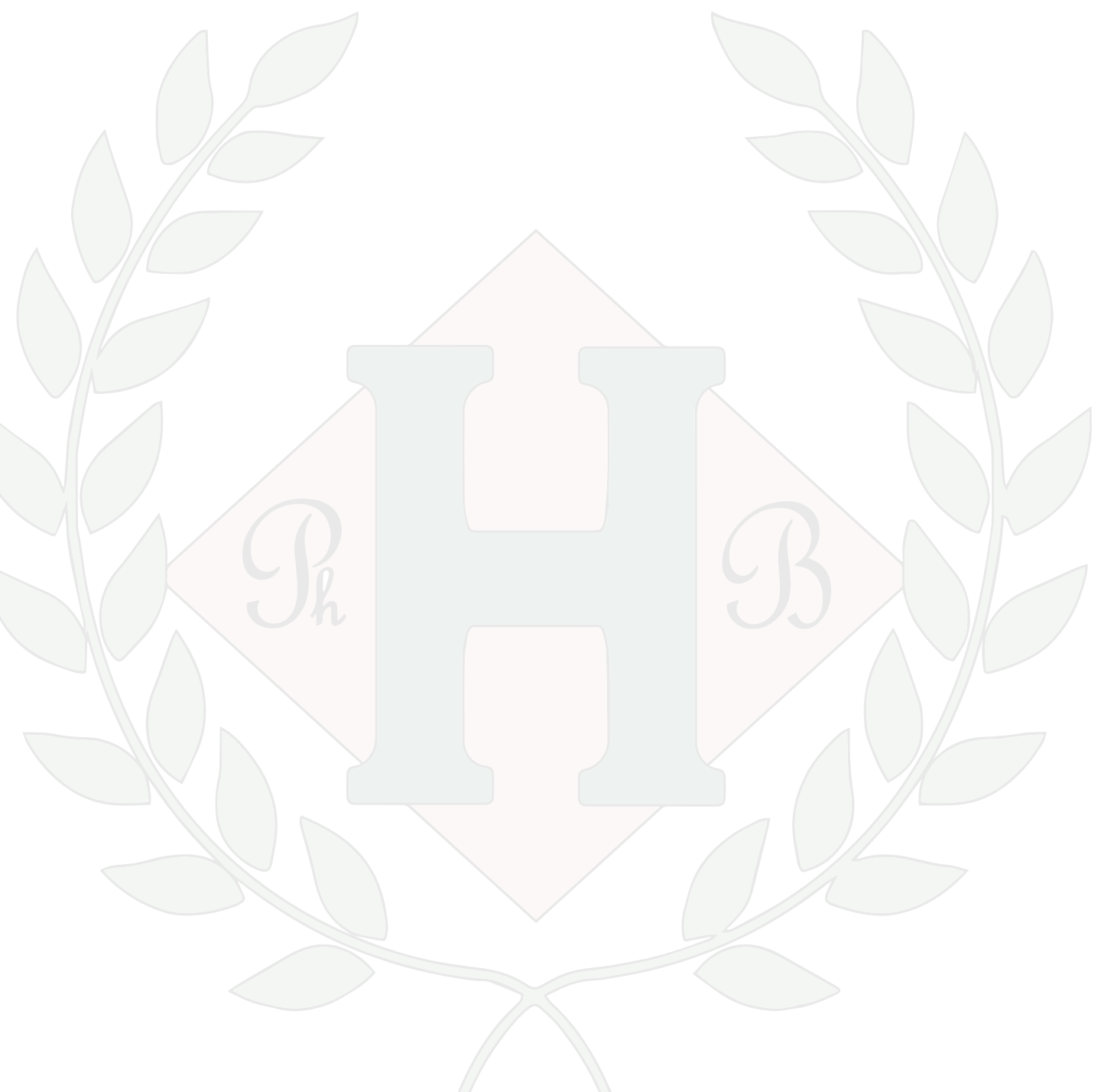

